\title{
Qualitative Health Research
}

http://qhr.sagepub.com/

Is Quality of Life a Healthy Concept? Measuring and Understanding Life Experiences of Older People

Fiona Hendry and Chris McVittie

Qual Health Res 2004 14: 961

DOI: $10.1177 / 1049732304266738$

The online version of this article can be found at:

http://qhr.sagepub.com/content/14/7/961

\author{
Published by: \\ (\$) SAGE \\ http://www.sagepublications.com
}

Additional services and information for Qualitative Health Research can be found at:

Email Alerts: http://qhr.sagepub.com/cgi/alerts

Subscriptions: http://qhr.sagepub.com/subscriptions

Reprints: http://www.sagepub.com/journalsReprints.nav

Permissions: http://www.sagepub.com/journalsPermissions.nav

Citations: http://qhr.sagepub.com/content/14/7/961.refs.html

>> Version of Record - Aug 2, 2004

What is This? 


\title{
Is Quality of Life a Healthy Concept? Measuring and Understanding Life Experiences of Older People
}

\author{
Fiona Hendry \\ Chris McVittie
}

The concept of quality of life has received considerable attention as an inclusive notion of health and as a basis for health interventions. The authors' argument in this article is that notwithstanding this attention, little consensus exists as to definition of the term. In addition, a focus on measurement has led to the neglect of wider aspects of quality of life. Such difficulties are particularly relevant to the study of quality of life of older people. Analysis of interview data suggests that older people's understandings of quality of life are not readily measurable and should be viewed in terms of phenomenological experience. The authors discuss the implications for studying quality of life of this group and difficulties for the concept itself.

Keywords: quality of life; subjective experience; older people; assessment; phenomenology

$\mathbf{T}$ he concept of quality of life has in recent years attracted ever-increasing interest from health psychologists and professionals alike for two main reasons. First, in many cases, the emphasis in health care provision has changed from a narrow one of symptom diagnosis and treatment to a more holistic view of the health of the individual: Health service providers have increasingly shifted from a symptombased approach to a focus on wider aspects of morbidity and the effects of chronic illness (Bowling, 2001). Quality of life as an inclusive notion of health with which everyone can identify has come to reflect this all-encompassing concept of wellbeing. Second, the efficacy and cost-effectiveness of medical interventions are increasingly of prime consideration in the delivery of services (Sollano et al., 1998). There is, accordingly, a need, wherever possible, to evaluate the impact of any health interventions made. The current range of measures relating to quality of life and its improvement (see Browne, McGee, \& O'Boyle, 1997) appear to offer the possibility of evaluating improvements in health in the widest sense. It is unsurprising, therefore, that quality of life as a concept has come to receive the marked attention of those working in this area.

Our argument in this article, however, is that notwithstanding the recent rise in popularity and apparent promise of quality of life as a concept, its applicability to

AUTHORS' NOTE: We would like to thank the anonymous referees who gave valuable and detailed comments on an earlier draft of this article.

QUALITATIVE HEALTH RESEARCH, Vol. 14 No. 7, September 2004 961-975

DOI: $10.1177 / 1049732304266738$

(C) 2004 Sage Publications 
the broad domain of health intervention remains in question. Despite the familiarity of the term, it should not be assumed that researchers, health service providers, and the public all share a common understanding of the notion. The current emphases on quality of life as a basis for intervention and on measurement for the evaluation of changes have led to the neglect of wider and more meaningful aspects of individual health. At the same time, the unquestioned use of the term quality of life masks considerable and little-examined conceptual difficulties. To explore such aspects, we examine in the present study individual understandings of the concept of quality of life. These understandings are considered in relation to the views of one group for whom quality of life has become ever more important, namely older people. As will be seen from this exploration of the views of older people, their understandings differ considerably from the conceptualizations of quality of life found in many measures currently in use. These individuals' subjective experiences, however, shed new light on the phenomenology of quality of life itself and, furthermore, can be used to inform its use in future health service provision in general and toward older people in particular.

\section{ASSESSMENT AND EXPERIENCE OF QUALITY OF LIFE}

In spite of quality of life's being a commonly used concept, there is little agreement in the research literature and in practice as to what the term actually describes. A main source of contention relates to whether quality of life should be regarded as referring to the objective quality of a person's external environment or to an individual's satisfaction with his or her own life (Rogerson, 1995). Lawton (1999), for example, has argued that quality of life comprises two objective components, namely behavioral competence and environmental quality, and two subjective components, namely perceived quality of life and psychological well-being. Little guidance, however, is offered as to how these disparate elements can be usefully combined into one operational construct.

Notwithstanding the lack of consensus as to what quality of life encompasses, research into the concept has flourished. Indeed, the very absence of conceptual agreement has been reflected in the number of tools that have been developed to measure quality of life (Bowling, 2001). Between 1990 and 1999, the number of new reports on the development and evaluation of quality-of-life measures rose from 144 to 650 per year (Garratt, Schmidt, Mackintosh, \& Fitzpatrick, 2002). Of these, some are generic measures, but the majority of tools target disease-specific assessment of quality of life (Bowling, 2001). Many of these tools, however, offer little definition of what is being measured. Although the term quality of life is used, this, according to Bowling (2001), is used often as a proxy for health, functional ability, or psychological well-being. In consequence, the notion of quality of life commonly masks differences both in conceptual terms and in terms of assessment or measurement (see, e.g., Farquhar, 1995a; Taillefer, Dupuis, Roberge, \& Le May, 2003).

The development and use of assessment tools has also attracted wide criticism for its predominant emphasis on objective aspects of quality of life and lack of attention to subjective experience (e.g., Addington-Hall \& Kalra, 2001; Garratt \& Ruta, 1999; Joyce, McGee, \& O’Boyle, 1999). Instruments that are intended to be generally 
applicable and to provide measurable data, it is argued, will inevitably overlook individual understandings. Calman (1984), for instance, has argued that quality of life is an entirely subjective concept to which every individual attaches meaning but that the meanings vary among individuals. From this standpoint, comparison between individuals is a difficult, if not impossible, proposition.

The lack of attention given to individual understandings by measurement tools currently in use can be seen to result in two particular difficulties for this approach. First, the ratings individuals give for aspects of their lived experiences often do not appear to correspond with observed circumstances. For example, evidence suggests that people with illness do not necessarily report a poorer quality of life than healthy individuals (Evans, 1991). These findings lead to a disability paradox (Albrecht \& Devlieger, 1999) whereby apparently adverse external circumstances are not reflected in individual experience (Koch, 2000; McMillan \& Weitzner, 1999). This, again, raises the question of what, in fact, quality-of-life tools can and do measure. Second, the extent to which quality of life can be measured as a discrete construct is questionable. Carr, Gibson, and Robinson (2001) have argued that quality of life, insofar as it has an objective component, is bound up with individual expectations. Consequently, when a particular goal is no longer attainable, the individual might replace this with a more achievable aim. Thus, expectations are altered to maintain the individual's sense of the quality of his or her life notwithstanding changes in circumstances (Carr et al., 2001). Quality of life, accordingly, can be considered a dynamic construct that is under constant review (Allison, Locker, \& Feine, 1997). Changes in expectations and fluctuating experience, again, pose a problem for any attempts at measurement.

A recent important and highly influential contribution to the debate on assessment of quality of life has been the involvement of the World Health Organization (WHO). The WHO has attempted both to define the concept and to develop appropriate assessment tools (WHOQOL Group, 1998a, 1999). Developers of these tools have sought to incorporate both subjective and objective elements. Starting from the view that quality of life is a subjective and broad-ranging concept (WHOQOL Group, 1998a, 1998b), the WHO sought to identify and test various facets of quality of life and examine in cross-cultural studies how these facets relate to the concept. Following focus group research with participants across a number of cultures, the WHO identified four broad domains as being universally relevant to quality of life, namely physical health, psychological well-being, social relationships, and environment (WHOQOL Group, 1999). These four domains have been incorporated into the assessment tools developed as a result of the research, namely the WHOQOL-100 tool and the short version, WHO-BREF. Following an initial test of its validity and sensitivity to changes in the clinical condition of depression (Skevington \& Wright, 2001), the WHOQOL-100 is now ready for use in clinical trials in the United Kingdom.

What the WHOQOL-100 ostensibly offers is a broad and wide-ranging basis for assessment of many aspects of quality of life for all individuals. In this, it appears more inclusive and all-encompassing than many other available instruments. The apparent inclusivity of the WHOQOL-100 comes, though, at a price: Little room remains for examination of any subjective experience of quality of life. Instead, quality of life is formulated as a standard set of life circumstances that everyone would aim to attain. In the search for and development of an instrument that can be 
used across cultures and for any individual (see Skevington, 2002), understanding of individual experience has given way to general laws of health. To what extent, therefore, the WHOQOL-100 represents an advance on and solution to the problems found with previous attempted measures remains open to question.

\section{QUALITY OF LIFE AND OLDER PEOPLE}

The difficulties encountered with quality of life as a concept, as discussed above, become all the more evident in relation to older people. Although older people make up a key and growing group of individuals within the United Kingdom, relatively little work to date has examined quality of life in the elderly population. Of 3,291 reports on the development and evaluation of quality of life tools, only $8 \%$ relate to older people (Garratt, Schmidt, et al., 2002). Many of these measures have been designed for limited use with particular subgroups of older people (McKee, Houston, \& Barnes, 2002) or focus narrowly on the illnesses or diseases that arise more frequently in the older person (Bowling, 2001). Despite the assertion by health psychologists that a holistic model of health has been adopted, there has been a tendency to limit this to examination of the relationship between psychological and biological variables (Chamberlain, Stephens, \& Young, 1997). The WHO tools, for example, were developed based on a sample of which $50 \%$ of participants were under 45 and $50 \%$ were over 45 . There has, however, been no subsequent examination of how the tools that were developed reflect the evaluation of quality of life by older people (Jirojanakul \& Skevington, 2000; Power et al., 1999). Similarly, there is a lack of research into how older people make sense of their quality of life. There is, therefore, a need for further research in this area for an understanding of the requirement and values of people at this stage in their lives (Bowling, 2001; Higgs, Hyde, Wiggins, \& Blane, 2003).

Previous work does, however, provide some indication of issues that are particularly important to older people. For instance, older people regard social contacts as highly important (Farquhar, 1995b). Issues such as choice and autonomy might also affect quality of life (Davies, Ellis, \& Laker, 2000; Langer \& Rodin, 1976; Nystrom \& Segesten, 1994). Recently, researchers have found that for older people living in long-term care environments, improved quality of life might be related to enhancing personal control in everyday life (Duncan-Myers \& Huebern, 2000).

In addition, change of health, social, and personal circumstances might become significant as people grow older. Lundh and Nolan (1996) suggested that processes such as accommodation might mediate the quality of life of some elderly people, whereby goals are altered as earlier expectations become unattainable. This might help to explain possible processes involved in the subjective assessment of quality of life, but there has been no further research to examine this theory with regard to the quality of life of older people. Quality of life among older people as a subjective dynamic construct still needs further investigation (Allison et al., 1997; Lawton, 1999).

The aim of the present study, accordingly, was twofold. First, we aimed to address in part the relative lack of research into the quality of life of older people. In view of continuing demographic changes within the United Kingdom and the key life changes commonly addressed by older people, such as incidence of chronic ailments and physical difficulties, there is a pressing need for a better understanding 
of quality of life within this age group. Second, we wished to explore the relationship between the aspects of quality of life identified as being universally relevant (WHOQOL Group, 1998a, 1999) and individuals' understandings of these aspects in their own lived experiences. The specific research questions of the study were (a) How do older people understand their own quality of life? and (b) Do or can current methods of assessment reflect these understandings?

\section{DATA}

The data for this study came from a series of 10 semistructured interviews conducted with older people. Participants were aged between 70 and 82 . Two participants were male, and 8 were female. All attended and were recruited through day centers in Edinburgh, Scotland. The day centers selected were located in different parts of the city and attracted clients from a wide range of socioeconomic backgrounds. An institutional ethics committee granted ethical approval for the study.

We asked participants questions that focused on five main themes, namely physical health, psychological well-being, social relationships, environment (the 4 domains identified as relevant to quality of life by the WHO; see WHOQOL Group, 1999), and choice and control (identified by previous writers [e.g., Davies et al., 2000; Duncan-Myers \& Huebern, 2000] as being relevant to older people). In addition, the interview protocol contained general questions that allowed participants the opportunities to make relevant any aspects of quality of life not otherwise covered.

Interviews lasted approximately an hour and were conducted at the day centers that the participants attended. All interviews were tape-recorded with the participants' consent and later transcribed. Transcription was carried out to a level that included words, speech particles, and pauses (untimed) but omitted other features such as intonation or pace of speech. Punctuation marks such as commas and periods were added to improve readability of the transcripts. Pseudonyms were substituted for participants' names, and all data were otherwise anonymized to preserve confidentiality.

We carried out coding and analysis using interpretative phenomenological analysis (hereafter IPA) (Smith, 1996; Smith, Jarman, \& Osborn, 1999). IPA emphasizes interpretation of individuals' perceptions of the topic of study and how these are reflected in themes and patterns in the data. In conducting the analysis, a set of themes is produced from the data and revised as necessary as analysis proceeds. New extracts are checked against emerging themes to ensure relevance of the analytic framework. Using this approach in the present study, we initially explored transcripts on a case-by-case basis for initial indicators of participants' understandings. We then examined indicators that were identified for their relationship to each other and checked them against further extracts. We identified further indicators from subsequent transcripts. We then grouped these indicators into emerging themes, which we checked for relevance against all transcripts in the data set. Analysis continued on an iterative basis, and we revised emerging themes until the analytic framework usefully accounted for the participants' understandings and we could identify no further themes from the transcripts. Following this analysis, we identified four main themes, discussed below, as being of prime relevance in this study. 


\section{ANALYSIS}

In the course of the analysis, four main themes, namely holism of experience, relativity to others, ambivalent views, and management of quality of life, emerged. These themes and their subjective meanings are considered in turn below.

\section{Holism of Experience}

Although the questions put to the interviewees were based on five main topics, it soon became apparent that the participants did not view separate aspects of quality of life as falling into distinct domains. In the course of the interviews, they commonly linked one aspect of quality of life to other aspects of experience.

Everyone would say, get up, go out, why don't you?_-good god-imagine bumping into me at Tescos. You are trying to fill your trolley and I'm getting pushed along and I'm trying to stretch over-people haven't got time for that. (Valerie)

In the above extract, Valerie refers to a health-related issue, a difficulty of movement. Limitations arising from this difficulty, however, are not described in relation to health. Instead, she describes the health difficulty in relation to its consequences for another activity, shopping. The extract provides a good example of the healthrelated experiences described by the participants. Here, health is viewed not as a unitary and discrete aspect of lived experience but, rather, as something that is inextricably linked to a range of activities making up everyday life.

The relationship between health and other aspects of life can be seen also in the following extract:

I like to go to Safeways, I know people laugh at this-I like to go to Safeways on a Friday and get my messages on a Friday and I manage to get to go myself-as I say his life has completely changed with him being in quite a lot of pain-and it can be a little stressful [Stressful for you?] yes, very stressful. So when I get out on Friday-he let's me get out, and I keep saying-when I get outside the door, I'm free, I'm free. (Morag)

Above, the emphasis placed on shopping as an activity can be seen clearly. For Morag, the ability to go shopping on her own is related not just to her health but also to the health of her husband and the social arrangements between them. The activities that she considers important in her life cannot simply be separated out but are interlinked in allowing her to live as she would obviously wish ("I'm free").

A similar interconnection of different life domains can be seen in the descriptions below:

It's, how do you put it-I live in a very quiet bit of E. and what I find is that at firstcame here to live-there was a lot of older people because it was housing built for the older people, but then they bought - which we did as well and a lot of younger single people came in - thing like that you know - and its quite a changing population and its quite lonely-you know. (Jane)

When I had my accident, when I got on the bus I thought it was great. I was in agony, the step was that high, but I thought great. I'm living again. (Barbara) 
Again, when describing particular aspects of life, the participants in the above extracts refer to the implications of one domain of quality of life for other domains. Jane states that she lives in a quiet area. This description might be thought to suggest contentment with living in a safe and peaceful environment. It soon becomes apparent, however, that environment is regarded as having a negative rather than a positive quality. The effects of environment are viewed as going beyond living in a particular area itself to social contact. Here, the perceived absence of neighbors of a similar age to the interviewee leads to a feeling of a lack of suitable opportunities for social interaction. Barbara refers to health, describing difficulty of movement resulting in great pain. Again, this description might be thought to reflect quality of life in relation to that aspect, in this case a negative experience. The perceived effects, though, also run counter to the initial suggestion, subsequently being described by the interviewee as "great." In each case, the immediate description is at odds with the subsequent view of experience, a view that arises from the impact of one aspect of life on others and reflects a wider view of quality of life than would fall within a single domain.

What all participants described, then, and can be seen in the extracts above, was the experience of different aspects of quality of life as being inextricably linked. The subjective experiences of these interviewees did not break down into separate categories, each of which could be assessed on its own merits. Instead, quality of life was regarded as a subjective whole that affected all parts of their everyday lives. Experiences of the interaction of many components of life and their effects on each other provided more holistic views of quality of life.

\section{Relativity to Others}

Although the interviewees took a holistic view of their experiences, their interpretations of quality of life were not regarded as being totally self-contained. Commonly, quality of life was regarded as relative to the experiences of other people.

For myself family is important-I am in the happy position that my family are better off than I am and have a far better quality of life than I ever had so I can sit back and there's no commitment necessary on my part_-it's there, but no-one's depending on me any more that I am dependent on them. That's a great relationship. I don't have to think about it—it's just automatic. (Bill)

Often, the relationships between people, especially older people, and their families are assumed to be quite straightforward: More contact will lead to improved relationships and, ultimately, to a better quality of life. On such a view, the relationship between family and quality of life is unproblematic. In this extract, though, the somewhat more complex nature of the link between family and satisfaction becomes apparent. For Bill, improved quality of life comes not from greater contact with family members but, instead, from the knowledge that family members appear to enjoy a better life than he did at a similar age. Paradoxically, this leads to the suggestion that less, rather than more, contact leads to increased quality of life, by allowing him to pursue life in other directions. The interviewee thus sees quality of life as dependent on the circumstances of others, in this case members of the family. 
Many participants saw their quality of life as relative to people other than family. Consider, for example, the following extracts.

I think it is a bit inevitable-there must be a very small percentage of elderly people who don't see their abilities fading away. It's one thing or something else that has deteriorated. I certainly feel shortness of breath and aches and pains-spongilitis in my neck. It was that bad I was getting four kinds of headache at once. I find that mentally I'm a bit slower. I don't think I know any less, but it does take longer to recall it-to achieve it. I say, but count your blessings, if they say they've broken their ankle-at least you are still active. So that's my-there are a lot of people worse than I am. (Jack)

I wouldn't like to live anywhere else. I live in a square-they are nearly all elderly and everybody is just as friendly, and if you see them, they stop and have a wee chat-eh-its quiet and its-I like it. I feel happy—and safe [Interviewer: Safe?] yes that's very important. Mind you there's some days after my daughter has taken me for the day - we go shopping - and to the bingo and once she goes away and I turn the key-there's sometimes I'm down. It's just turning that key-I mean-I was married for 46 years and that's a life time, and then when you're left I mean it-it is a-it is hard-and then I say to myself. I'm on my own and there's people worse than me. (Linda)

Jack describes health by referring to particular symptoms and their effects. These would appear to affect life choices considerably and are regarded as having led to reduced abilities. Such difficulties, however, are regarded as a normal part of the aging process and, as such, typical of older people in general. Linda portrays aspects of environment positively. These are seen as linked to other parts of daily life, namely interaction with family others, as part of a holistic frame of reference discussed above. This wider view of experience, however, also includes negative elements such as isolation, also linked to environment, which might indicate dissatisfaction with much of everyday life. Both participants, though, follow these potentially negative descriptions with a comparison of their experiences with those of other people. In terms of these comparisons, the participants rate their experiences positively and consider themselves to be better placed than other people.

In the course of the interviews, many participants provided comparisons such as those seen above. Commonly, the comparisons that were provided related their experiences to those of other people generally or of other older people in particular. Participants often described health, for instance, in terms that indicated stoical acceptance of current abilities that were reduced but remained better than the capabilities of others of similar ages. Such comparisons allowed them to view any difficulties as relatively unimportant in their lives overall. For the interviewees, they, accordingly, represented positive evaluation of current circumstances, even circumstances that others might regard as negative.

\section{Ambivalent Views}

One feature of the interviewees' experience discussed above was that aspects of life were commonly interlinked, giving rise to experiences that had both positive and negative elements. Quality of life as a whole, therefore, encompassed a variety of differently evaluated experiences. In many cases, however, inconsistent evaluations could be found in relation to the same factor, for example, 
Some just get a visit once a week-not all by any means-some have very dedicated-sons who move in with their mother to look after them and the other way is when the elderly one goes to live with them-then they've got their benefit books, disability allowances. There's two sides to every bit of it - the good and the bad. (Jack)

Above, Jack summarizes the experiences of a number of older people. These experiences vary both in terms of the regularity of contact that older people have with their families and the living arrangements available to people. Living with family members, an arrangement that might ordinarily be regarded as preferable to other possibilities, is viewed as bringing with it a loss of financial independence. It is, accordingly, not seen as a totally desirable provision. The interviewee, however, views all possibilities as being alike in this regard, in that all offer advantages and disadvantages. Any form of living arrangement is, therefore, regarded as inevitably ambivalent in what it offers for the older person.

A similar ambivalence is found in relation to many facets of life; for instance,

I've only got one sister-and she's in B.—she's good. I see her every day-she'll bring something for me to eat, food for me. She's good like that-if I want any particular thing - she'll go and get it for me, but I find it difficult-because her taste is not mine [Interviewer: You're not the same-you are different people] Totally different. You've got to tell her that without standing on her feet. (Valerie)

Again, Valerie describes what would be accepted as a positive feature of life, having regular daily contact with a family member who brings food and other items as required. This too, though, is not considered to be an altogether positive aspect of life. Differences between Valerie and her sister lead to problems in maintaining individual preferences and difficulties in communicating these between them. Although the overall evaluation of the situation is positive, this encompasses a combination of both positive and negative points.

A combination of both positive and negative feelings was found in relation to other domains, as seen below:

You have this love-hate relationship with your house, you know, once you go home and its dark and you pull the curtains down-you're in a tomb-there's no speaking voice-somebody said, you've got a television-I said — but I can't argue with a television. (Barbara)

Here, Barbara refers to positive and negative aspects of living at home. The description implies that some features of being at home are enjoyed. It is, however, the less favorable ones, such as the sense of isolation and lack of interaction, that are stated in detail. The house is regarded as incorporating both the positive and negative parts of life, which have come to be associated with it, providing the interviewee with a clearly ambivalent experience of environment.

For the interviewees, then, the same components of their lives can result in experiences that are rated both positively and negatively. It, accordingly, becomes problematic to provide an overall evaluation that does justice to the range of feelings surrounding, for example, contact with family that inhibits individual preferences or a home environment that brings both security and loneliness. The participants appear only too aware of the complexity of issues tied up with such elements 
of their lives and in relation to which they have to make sense of their everyday experiences.

\section{Management of Quality of Life}

The features of the interviewees' responses examined this far all indicate that quality of life is seen as a multifaceted, complex, and equivocal experience. More than this, however, it became clear in the course of the interviews that the participants did not regard quality as in any way simply comprising a passive experience that affected their lives in these ways. Rather, they described quality of life as a phenomenological process that they could control. For example,

I see my daughter-she stays in B.-son stays here, but I very rarely see him-he
comes up now and again, but no-they've got their own life and I've got to make my
own life-and that's what I'm doing and I'm enjoying every minute of it. (Annie)
If you be defeatist-you're never going to have any quality of life-I mean as I say
there have been times when I have felt defeated. Next day Ijust bounce back. (Cath)

In the two extracts above, the interviewees describe what might be heard as negative parts of their lives. The consequences to Annie of a lack of regular contact with family are implicitly difficult, suggesting possible loneliness and isolation. Cath makes the impact on quality of life of accepting a sense of despair explicit in extreme terms ("you're never going to have any quality of life"). It soon becomes apparent in each case, though, that neither participant is prepared to accept such negative consequences. Both speakers instead describe the actions that they take to prevent the negative outcome suggested and to achieve a more positive sense of well-being. Thus, they manage their responses to individual experiences to increase their perceived and understood quality of life.

In these two extracts, then, we see examples of how the interviewees view quality of life as something they manage themselves. Quality of life, however, is regarded as manageable also with respect to other people, as seen below:

I can't think-I'm more or less a happy person-I can put a front up-that as well, but on the whole I'm more or less happy-I have my off days-things like that-I bounce back again. You try to hide your feelings half the time. (Linda)

Similarly to the two previous speakers, Linda describes events with a potentially negative impact ("off days") and how she controls them to maintain an overall sense of satisfaction with life. Here, though, control of quality of life is considered for its impact beyond the individual. The appearance to others of the quality of life enjoyed by the interviewee also becomes important. In particular, Linda introduces a distinction between actual quality of life as experienced and that presented outwardly ("a front," "hide your feelings"). There is, consequently, a private/public contrast in what is known about quality of life. As a result, quality of life is considered to be essentially a personal experience, ultimately knowable only to the individual concerned.

From these interviewees, then, quality of life can be seen to be a highly subjective phenomenon in two ways. First, the quality of life is considered to be a process 
of managing individual experience to achieve a sense of well-being rather than a state of life. In this way, it can be viewed as an active project under continual monitoring and adjustment. Second, the experience of the inner process might or might not be communicated to outside observers: Appearances of quality of life are also manageable, whereas the underlying experience remains highly personal. Both of these aspects of subjective experience present particular problems for attempts to assess quality of life in any objective way. The implications of these and the other features of subjective experience, identified above, for attempts at assessment and measurement are discussed below.

\section{DISCUSSION}

The questions put to the participants in the present study were based on five topics derived from the WHOQOL-100 and previous research. The participants invariably and freely responded to these questions, suggesting that they regarded the topics as relevant to their lived experiences, yet their responses put in doubt the usefulness of attempting to assess quality of life for this group in this way. This is not because the respondents failed to make sense of these general descriptions; rather, the ways in which they did so clearly displayed the complex nature of individual experience. Such complex descriptions and the ensuing problems for assessment and measurement of quality of life can be seen in relation to each of the four themes identified in the present study.

A first difficulty arises in relation to the issue of fragmenting experience. In their attempts to obtain detailed data, measures of quality of life require that respondents provide information under discrete headings, four separate domains in the case of the WHOQOL-100. It is clear, however, that when offered the opportunity to give a more general picture, people do not segment their lives into component parts. As seen in the present study, health is commonly regarded as affecting other aspects of experience, such as activities like shopping. Similarly, a home environment, however desirable, can be experienced as having negative effects on opportunities for social contact. Given such interlinking of different realms of experience, it is unsurprising that previous writers have found that people often have difficulty in assigning importance to separate facets of life (Carr et al., 2001; Coen, O'Mahoney, et al., 1993). As Bowling (1995) has suggested, the use of forced choice items to elicit information can produce data that are somewhat different from those obtained in more open-ended ways, which allow participants to describe their experiences in terms that have greater relevance to their everyday lives.

Views of quality of life reflected also a contextual relationship with other people. During the interviews, participants often compared their own experiences to those of others, such as older people in general. This finding calls into question the assumption that quality of life can be assessed on a purely individual basis, with contextual aspects of experience being viewed as distinct from the experience itself. VanderZee, Buunk, and Sanderman (1995), for example, have argued that comparisons with others should be viewed as a mechanism for coping with adverse experience as distinct from being part of the evaluation itself. As with other health matters, however, treatment of context in this way arises only from assessment through tools that have insufficient regard for the social and everyday situations in which people 
make sense of their lives (see Spink, 1999). Understood from the participants' perspective, the relatedness of their experience to that of other people is an intrinsic part of their quality of life rather than an epiphenomenal effect. It is not, though, a part that is readily amenable to measurement.

A further difficulty for measurement comes from the third theme identified in the analysis above, namely ambivalence. Operationalizing quality of life on a series of fixed-point scales requires that one response be given in each case. The WHOQOL-100, for instance, assumes that the effect of home environment on quality of life can be assessed in a linear and unproblematic way. The participants did not share this view. A neighborhood could be "friendly" and liked, and the individual could be "lonely" at the end of the day. Participants would describe a "love-hate relationship" with their homes, as Barbara did. The assumption that such aspects of life can be readily reported on a unilinear scale is, again, found wanting (Mallinson, 1998) and fails to reflect the complexity of personal experience. Viewing experiences in such a manner runs the risk of ignoring the richness and diversity of data otherwise available.

It is, however, the finding that quality of life is seen as an active project that brings the greatest difficulties for measurement. Previous researchers have already questioned whether measures of quality of life reflect existing states of being or are confounded by participants' expectations (Carr et al., 2001). If perceived quality of life varies not just with expectations over time but on an ongoing, daily basis, then it becomes questionable which part of the process, if any, is captured by measurement. This question is all the more pertinent when taken together with the indication that participants choose which aspects of quality of life to make public and which will remain private. Possible concealment of private views of quality of life is consistent with previous work in this area. Avis and Smith (1998), for example, found that in comparison to younger respondents, older people had lower response rates for quality of life questionnaires and produced higher rates of socially desirable responses. It therefore becomes questionable whether the use of questionnaires can produce a meaningful understanding of quality of life in this group without having regard also to the ways in which they make sense of their lived experiences as an ongoing subjective process (see, e.g., Allison et al., 1997; Yardley, 1999).

In this study, we examined the experiences of older people as a homogenous group. All those who took part were active and enjoyed social contact and participation in the day centers that they attended. Their experiences cannot necessarily be said to be typical of all older people, particularly the less active elderly population. The present findings, though, might throw some light on difficulties encountered in other studies. McKee et al. (2002), for instance, in a study of the frail elderly, obtained very low response rates for a number of quality-of-life measures used among this population. Irrespective of other data obtained, such rates suggest that in many cases, the instruments employed provide limited opportunity for people to describe personal experience in terms relevant to them (see also King, Carroll, Newton, \& Dornan, 2002).

Neither does it automatically follow that the issues identified here as being most relevant to older people are necessarily those also of the population more widely. Clearly, a number of factors, such as the possibility of poor health and its impact on other aspects of life, are more salient for older people than perhaps for other sectors of the population. 
Quality of life as a construct, however, is relevant not just for older people but for the population in general. What the present study does show are some of the difficulties inherent in the concept. The possible disparity between measured perceptions and subjective experience suggests that it is indeed possible, if not likely, that quality of life has often come to be a proxy for other constructs, such as health, functional ability, or psychological well-being (Bowling, 2001; Taillefer et al., 2003). Widespread use of the term thus continues to reflect many conceptual differences. These differences and the resulting confusion put in question the continuing usefulness of quality of life as an all-encompassing concept in health settings. Nevertheless, the inclusiveness it promises as a broad-ranging indicator of health and as a basis of evaluating health interventions make it unlikely that researchers and practitioners will readily abandon the concept in favor of other tools (Michalos, 2004).

Our argument here is that two main steps are required to address the ongoing conceptual problems with quality of life. First, there is a need for greater precision on the part of all who use the term. Where the focus is on measurement of areas of experience, clarity is required as to what is actually being tapped into and measured by the instruments that are used (Jones \& Kaplan, 2003). It is surely more helpful, wherever possible, to argue the case for constructs such as functional ability or psychological well-being in their own terms instead of bringing them under the catchall umbrella of quality of life. These constructs should not be regarded as having any lesser value than quality of life, however; rather, precision in the description used might usefully inform research and health intervention in a range of possible situations.

A second step required is the development and use of quality of life as an inclusive notion. This becomes all the more important given the central role that it has assumed in this area. The findings of this study would suggest that a measurement instrument, even one as highly researched and developed as the WHOQOL-100, cannot elicit the full range of subjective experience of quality of life. At best, the measurements obtained can provide only part of a greater overall picture. For a more complete understanding, therefore, these measures need to be complemented by other techniques that are more sensitive to differences and ambiguities in individual experience. In their choice of techniques, however, researchers and practitioners should pay particular attention to the individuals concerned in each case and be flexible in the choice of methods used to gain insights into quality of life in the widest sense. One approach does not fit all; methods such as structured interviews that have previously been used successfully with some groups (Coen, O'Boyle, Swanwick, \& Coakley, 1999; Coen, O'Mahoney, et al., 1993) have failed to provide useful data for others (McKee et al., 2002). In the future development of quality of life, techniques such as diary methods (see, e.g., Dworkin \& Wilson, 1993) or semistructured interviews, for instance, might produce insights into the subjective experiences of many individuals. Combined with other measures, these promise to yield a more holistic picture of quality of life of those concerned than a reliance on individual methods and their limitations. Given the current scope and conceptual diversity of quality of life, its future use and development should appropriately adopt a multimethod approach that does justice to the broad concept. 


\section{REFERENCES}

Addington-Hall, J., \& Kalra, L. (2001). Who should measure quality of life? British Medical Journal, 322, 1417-1420.

Albrecht, G. L., \& Devlieger, P. J. (1999). The disability paradox: High quality of life against all odds. Social Science \& Medicine, 48, 977-988.

Allison, P. J., Locker, D., \& Feine, J. S. (1997). Quality of life: Adynamic construct. Social Science \& Medicine, $45,221-230$.

Avis, N. E., \&Smith, K. W. (1998). Quality of life in older adults with HIV disease. Research on Aging, 20(6), 822-845.

Bowling, A. (1995). What things are important in people's lives? A survey of the public's judgements to inform scales of health related quality of life. Social Science \& Medicine, 10, 1447-1462.

Bowling, A. (2001). Measuring disease. Buckingham, UK: Open University Press.

Browne, J. P., McGee, H. M., \& O’Boyle, C. I. (1997). Conceptual approaches to the assessment of quality of life. Psychology \& Health, 12, 737-751.

Calman, K. C. (1984) Quality of life in cancer patients-A hypothesis. Journal of Medical Ethics, 10, 124-127.

Carr, A. J., Gibson, B., \& Robinson, P. G. (2001). Measuring quality of life: Is quality of life determined by expectations or experience? British Medical Journal, 322, 1240-1243.

Chamberlain, K., Stephens, C., \& Young, A. C. (1997). Encompassing experience: Meanings and methods in health psychology. Psychology \& Health, 12, 691-709.

Coen, R. F., O'Boyle, C.A., Swanwick, G. R. J., \& Coakley, D. (1999). Measuring the impact on relatives of caring for people with Alzheimer's disease: Quality of life, burden and well-being. Psychology $\mathcal{E}$ Health, 14, 253-261.

Coen, R., O'Mahoney, D., O'Boyle, C., Joyce, C. R. B., Hiltbrunner, B., Walsh, J. B., et al. (1993). Measuring the quality of life of dementia patients using the schedule for the evaluation of individual quality of life. Irish Journal of Psychology, 14(1), 154-163.

Davies, S., Ellis, L., \& Laker, S. (2000). Promoting autonomy and independence for older people within nursing practice: An observational study. Journal of Clinical Nursing, 9, 127-136.

Duncan-Myers, A. M., \& Huebner, R. A. (2000). Relationship between choice and quality of life among residents in long-term-care facilities. American Journal of Occupational Therapy, 54, 504-508.

Dworkin, S. F., \& Wilson, L. (1993). Measurement of illness behavior: Review of concepts and common measures. In P. M. Conn (Ed.), Paradigms for the study of behavior (pp. 329-344). New York: Academic Press.

Evans, R. W. (1991). Quality of life. Lancet, 338, 363.

Farquhar, M. (1995a). Definitions of quality-of-life: A taxonomy. Journal of Advanced Nursing, 22(3), 502508.

Farquhar, M. (1995b). Elderly people's definitions of quality of life. Social Science E Medicine, 41(10), 14391446.

Garratt, A. M., \& Ruta, D. A. (1999). The patient generated index. In C. R. B. Joyce, H. M. McGee, \& C. A. O'Boyle (Eds.), Individual quality of life: Approaches to conceptualisation and assessment (pp. 118-134). Amsterdam: Harwood Academic.

Garratt, A., Schmidt, L., Mackintosh, A., \& Fitzpatrick, R. (2002). Quality of life measurement: Bibliographic study of patient assessed health outcome measures. British Medical Journal, 324, 1417-1419.

Higgs, P., Hyde, M., Wiggins, R., \& Blane, D. (2003). Researching quality of life in early old age: The importance of the sociological dimension. Social Policy \& Administration, 37(3), 239-252.

Jirojanakul, P., \& Skevington, S. (2000). Developing a quality of life measure for children aged 5-8 years. British Journal of Health Psychology, 5, 299-321.

Jones, P. W., \& Kaplan, R. M. (2003). Methodological issues in evaluating measures of health as outcomes for COPD. European Respiratory Journal, 21(Suppl. 41), 13S-18S.

Joyce, C. R. B, McGee, H. M., \& O’Boyle, C. A. (Eds.). (1999). Individual quality of life: Approaches to conceptualisation and assessment. Amsterdam: Harwood Academic.

King, N., Carroll, C., Newton, P., \& Dornan, T. (2002). "You can't cure it so you have to endure it": The experience of adaptation to diabetic renal disease. Qualitative Health Research, 12, 329-346.

Koch, T. (2000). The illusion of paradox. Social Science \& Medicine, 50, 757-759.

Langer, E. J., \& Rodin, J. (1976). The effects of choice and enhanced personal responsibility for the aged: A field experiment in an institutional setting. Journal of Personality \& Social Psychology, 34(2), 191-198.

Lawton, M. P. (1999). Quality of life in chronic illness. Gerontology, 45, 181-183. 
Lundh, U., \& Nolan, M. (1996). Ageing and quality of life 2: Understanding successful ageing. British Journal of Nursing, 5(21), 1291-1295.

Mallinson, S. (1998). The Short-Form 36 and older people: Some problems encountered when using postal administration. Journal of Epidemiology \& Community Health, 52(5), 324-328.

McKee, K. J., Houston, D. M., \& Barnes, S. (2002). Methods for assessing quality of life and well-being in frail older people. Psychology \& Health, 17(6), 737-751.

McMillan, S. C., \& Weitzner, M. (1999). Quality of life in cancer patients: Use of a revised hospice index. Cancer Practice, 6, 282-288.

Michalos, A. C. (2004). Social indicators research and health-related quality of life research. Social Indicators Research, 65(1), 27-72.

Nystrom, A., \& Segesten, K. (1994). On sources of powerlessness in nursing home life. Journal of Advanced Nursing, 19, 124-133.

Power, M., Bullinger, M., Harper, A., \& The WHOQOL Group. (1999). The World Health Organization of WHOQOL-100: Tests of the universality of quality of life in 15 different cultural groups world-wide. Health Psychology, 18(5), 495-505.

Rogerson, R. J. (1995). Environmental and health-related quality of life: Conceptual and methodological similarities. Social Science \& Medicine, 41, 1373-1382.

Skevington, S. M. (2002). Advancing cross-cultural research on quality of life: Observations drawn from the WHOQOL development. Quality of Life Research, 11, 135-144.

Skevington, S. M., \& Wright, A. (2001). Changes in the quality of life of patients receiving antidepressant medication in primary care: Validation of the WHOQOL-100. British Journal of Psychiatry, 178, 261267.

Smith, J. A. (1996). Beyond the divide between cognition and discourse: Using interpretative phenomenological analysis in health psychology. Psychology \& Health, 11, 261-271.

Smith, J. A., Jarman, M., \& Osborn, M. (1999). Doing interpretative phenomenological analysis. In M. Murray \& K. Chamberlain (Eds.), Qualitative Health Psychology (pp. 218-240). London: Sage.

Sollano, J. A., Rose, E. A., Williams, D. L., Thornton, B., Quint, E., Apfelbaum, M., et al. (1998). Costeffectiveness of coronary artery bypass surgery in octogenarians. Annals of Surgery, 228(3), 297-304.

Spink, M. P. (1999). Making sense of illness experiences. In M. Murray \& K. Chamberlain (Eds.), Qualitative health psychology: Theories and methods (pp. 83-97). London: Sage.

Taillefer, M. C., Dupuis, G., Roberge, M. A., \& Le May, S. (2003). Health-related quality of life models: Systematic review of the literature. Social Indicators Research, 64(2), 293-323.

WHOQOL Group. (1998a). The World Health Organization Quality of Life Assessment (WHOQOL): Development and general psychometric properties. Social Science \& Medicine, 46(12), 1569-1585.

WHOQOL Group. (1998b). Development of the World Health Organization WHOQOL-BREF Quality of Life Assessment. Psychological Medicine, 28, 551-558.

WHOQOL Group. (1999). The World Health Organization WHOQOL: Tests of the universality of quality of life in 15 different cultural groups worldwide. Health Psychology, 18(5), 495-505.

VanderZee, K. I., Buunk, B. P., \& Sanderman, R. (1995). Social comparison as a mediator between health problems and subjective health evaluations. British Journal of Social Psychology, 34(1), 53-65.

Yardley, L. (1999). Understanding embodied experience. In M. Murray \& K. Chamberlain (Eds.), Qualitative health psychology: Theories and methods (pp. 31-46). London: Sage.

Fiona Hendry, M.Sc., is an independent scholar in Edinburgh, United Kingdom.

Chris McVittie, Ph.D., is a lecturer in social sciences, media, and communication at Queen Margaret University College, Edinburgh, United Kingdom. 